\title{
Effect of Age and Gender on Voice Onset Time: Data from Sinhalese
}

\author{
S.V. Narasimhan ${ }^{1 *}$, W.G.S.S. Karunarathne ${ }^{2}$ \\ ${ }^{1}$ Department of Speech Language Pathology, JSS Institute of Speech \& Hearing, JSS Hospital, Mysore, \\ Karnataka, India. \\ ${ }^{2}$ Speech Language Pathologist and Audiologist, Wickramarachchi Speech \& Hearing Institute, \\ Nugegoda, Sri Lanka.
}

Date Received: 18-02-2021 Date Accepted: 17-12-2021

\begin{abstract}
Objective: To documenting the voice onset time in voiced and unvoiced stop consonants in Sinhala and to investigating the effects of age and gender on voice onset time values in Sinhalese speakers.

Methods: Three groups of participants were employed. Group 1 included 20 children, Group 2 included 20 adults and Group 3 consisted of 20 elderly subjects. All the subjects spoke the dialect of central province of Sri Lanka. Words consisting of three Sinhala short vowels /a/, /i/ and /u/ in were recorded. Voice onset time values from two voiced and voiceless stop consonants were extracted.

Results: Voiced stop consonants had significantly longer voice onset time values compared to voiceless stop consonants. Significant effect of age as well as gender on voice onset time values were also observed. Conclusion: Supplementary investigations on the normative aspects of voice onset time among the Sinhala population would provide additional insights and validated tools for indexing the articulatory and acoustic characteristics of stop consonants in Sinhalese.
\end{abstract}

Keywords: Voice Onset Time, Sinhalese, Elderly, Sinhala, Acoustic analysis

\section{Introduction}

Voicing distinctions among the stop consonants frequently exists in most of the world's languages (Abramson \& Whalen, 2017). Voice Onset Time (VOT) is an aspect of vocalisation of stops that distinguishes between the voiced and unvoiced stop consonants (Olson, 2017). VOT is one of the temporal parameters that reflect the temporal interaction between the laryngeal and the supralaryngeal systems (Bae, 2020). VOT denotes the timing difference between the instance of the articulatory release of stop and the onset of the glottal pulse associated with phonation (Lisker \& Abramson, 1964). Even though there are other cues for voicing distinction, earlier researchers have reported that VOT as the most robust and reliable acoustic cue in distinguishing voiceless and voiced stop consonants (Abramson \& Lisker, 1973; Abramson \& Whalen, 2017; Lisker \& Abramson, 1964, 1967, 1971; Olson, 2017). VOT is categorised as either short lag (onset of the voicing begins considerably later than the transient), or simultaneous voicing (onset of voicing is simultaneous with a transient), or voicing lead or pre-voicing (voicing begins before the stop is released) (Lisker \& Abramson, 1964).

VOT is influenced by numerous factors other than the voicing feature of stop consonants. One of the most critical factors influencing VOT is the language (Alotaibi \& AlDahri, 2011; Davis, 1990;

*Correspondence: narasimhanslp@gmail.com

Tel: +919900789918

(C) University of Sri Jayewardenepura 
Manjunath et al., 2010; Mitleb, 2001; Olson, 2017; Savithri \& Santhosh, 2003). Lisker \& Abramson (1964), documented VOT across several languages. Eleven languages were classified into three groups based upon the number of stop categories in each language. Further, they proposed three ranges of VOTs, i.e., +60 to $+100 \mathrm{~ms}, 0$ to $+25 \mathrm{~ms}$, and -125 to $-75 \mathrm{~ms}$, and advocated that each stop category in these languages would fall under any one of these three ranges. The study concluded that the languages can be categorised under anyone groups with respect to their VOT values. (Lisker \& Abramson, 1964).

Cho \& Ladefoged (1999), categorised four groups of voiceless occlusive across 18 languages stop consonants with a VOT of $30 \mathrm{~ms}$ (unaspirated velars), stop consonants with a VOT of $50 \mathrm{~ms}$ (slightly aspirated velars), stop consonants with a VOT of $90 \mathrm{~ms}$ (aspirated velars), and stop consonants with a VOT of more than $90 \mathrm{~ms}$ (highly aspirated velars). Therefore, the VOT for the voiceless and voiced stops are not similar across all the languages. Even though the researchers have attempted to study the variation of the VOT values across the different languages, most of the researchers have documented the VOT across western languages, and very few researchers have investigated the VOT across the Indo-Aryan languages. As the earlier literature highlights the variation of the VOT values across the different languages, normative values of VOT have to be established for the stop consonants with respect to different languages.

VOT is also influenced by the speakers' age and gender (Ma et al., 2018; Peng et al., 2014; Whiteside et al., 2003; Whiteside \& Marshall, 2001; Yu et al., 2015). Past studies on speech development have also focused on VOT as an important temporal feature (Kent, 1976; Whiteside et al., 2003; Whiteside \& Marshall, 2001) and have reported that a typically developing children achieve adult-like VOT by eleven years of age, and during adolescence, they continue to refine their motor skills (Lundeborg et al., 2012; Whiteside et al., 2003; Whiteside \& Marshall, 2001; Yu et al., 2015). However, some inconsistencies have been noted in the age-related VOT changes described in the literature. Some studies have reported shorter VOTs in adults compared to children (Kent, 1976; Zlatin \& Koenigsknecht, 1976), whereas other studies have noted longer VOTs in adults compared to children (Barton \& Macken, 1980). However, the literature review shows consistent findings on the variability of VOT across age. Variability of VOT decreases from childhood to adulthood (Barton \& Macken, 1980; Koenig, 2001; Whiteside \& Marshall, 2001; Yu et al., 2015; Zlatin \& Koenigsknecht, 1976). These changes in VOT from childhood to adulthood were attributed to the changes in the anatomical and neuromotor maturation in speech mechanisms (Kent, 1976).

Even though the age-related VOT changes have been investigated, very few studies have extended their investigations to the elderly population. Sweeting \& Baken (1982) documented VOT in adult and elderly subjects and reported that there were no differences in the mean VOT values between the adult and elderly subjects, whereas the standard deviation of mean VOT values differed significantly between these subjects. Thus, it was inferred that variability in VOT increased with age. Benjamin (1982) found that geriatric subjects of American English had significantly shorter VOTs than younger subjects. On the contrary, Bóna (2014) investigated VOT changes in adult and elderly Hungarian individuals and reported that elderly subjects had longer VOT than that of young subjects. It is a known fact that the rate of speech decreases (Smith et al., 1987), articulation becomes less accurate and slower (Ballard et al., 2001; Torre $\&$ Barlow, 2009) as the age progresses. Even though these changes affect VOT, the information available concerning the changes in VOT in the geriatric population is inconclusive.

The research findings on gender-related differences in VOT are also not equivocal. Several studies have shown longer VOT values in females (Karlsson et al., 2004; Robb et al., 2005; Ryalls et al., 1997; 
Swartz, 1992; Whiteside \& Marshall, 2001), and other studies have found longer VOT values in males (Smith, 1978). Few studies have reported no differences in VOT between male and female subjects (Ryalls et al., 2004; Sweeting \& Baken, 1982). The gender differences in temporal aspects of speech production can be influenced by the differences in the vocal anatomy between males and females (Robb et al., 2005). However, these discrepancies in the findings of the earlier studies might be attributed to different sociophonetic factors and the cultural factors of participants involved in these studies (Whiteside \& Marshall, 2001).

Therefore, the review of literature on the VOT reveals that the VOT values vary in relation to language, age of the speaker, and gender. The above literature suggests that most of the studies on VOT are carried out on Western languages. The considerable need to establish normative values with respect to individual languages can be felt from the above literature. There is no well-documented literature in reporting the VOT values in Sinhalese language (Indo-Aryan language family spoken primarily in Sri Lanka). Sinhala also called Sinhalese is an official language of Sri Lanka spoken by its majority population numbering roughly about 13 million people. It is an Indo-Aryan branch of the Indo-European language family. Hence, the present study aimed at documenting the VOT in voiced and unvoiced stop consonants in Sinhala and to investigating the effects of age and gender on VOT in Sinhalese speakers. The present study tested the following three hypotheses (null hypothesis) - (1) 'there will be no significant differences between the VOT values of voiced and voiceless consonants in Sinhala language', (2) 'there will be no significant differences in the VOT values between the age groups in Sinhala language' and (3) 'there will be no significant differences in the VOT values between the genders in Sinhala language'.

\section{Methodology}

\subsection{Subjects}

The present study considered three groups of native Sinhala speaking subjects. Group 1 included 20 children in the age range of 7-11 years, Group 2 included 20 adults in the age range of 25-30 years and Group 3 consisted of 20 elderly subjects in the age range of 65-70 years. All the subjects spoke the dialect of central province of Sri Lanka. Each group consisted of ten male and ten female subjects. All the subjects were evaluated by an experienced Speech Language Pathologist to rule out any speech, language and cognitive disturbances. All the subjects had normal hearing sensitivity in the octave frequencies from 250 $\mathrm{Hz}$ to $8000 \mathrm{~Hz}$ in both the ears as per the audiometric testing. All the participants were monolingual native central province Sinhala speakers having no history of any hearing or language impairments. Convenience sampling was used to choose the subjects for the study. Informed consents were obtained from all the subjects or guardians/ parents in case of children.

\subsection{Test Material}

A reading passage in the Sinhala language (given in Appendix) was used as test material to elicit the stop consonants. The passage consisted of all the six stop consonants /p/, /t/, /k/, /b/, /d/, /g/. However, only four stop consonants, namely $/ \mathrm{p} /, / \mathrm{k} /, / \mathrm{b} /$ and $/ \mathrm{g} /$ were used for analysis in the present study as they occurred consistently at the medial position of the word. These four stop consonants were selected to maintain uniformity across all the groups in terms of the words used and to eliminate morphological variations, which would facilitate the comparison between each group.

*Correspondence: narasimhanslp@gmail.com

Tel: +919900789918

(C) University of Sri Jayewardenepura 


\subsection{Procedure}

The recording was carried out in a sound-treated room used for audiometry, which met the ANSI specifications prescribed for hearing evaluation(ANSI S3.1, 2013). The room was free from distraction and had a comfortable temperature and well lit. Each subject was seated comfortably in a chair and the reading passage in the Sinhalese language was placed on a table in front of the subject. Each participant was asked to read the passage in his/her comfortable pitch and loudness. The microphone was placed at a distance of $15 \mathrm{~cm}$ from the participant's mouth. The speech sample was recorded onto the Praat software (version 5.3.23). All the samples were digitised at a sampling frequency of $44.1 \mathrm{~Hz}$ and 16 bits/sample quantisation.

\subsection{Data analysis}

VOT four stop consonants $/ \mathrm{p} /, / \mathrm{k} /, / \mathrm{b} /$, and /g/ were extracted. VOT was measured as the time value (in milliseconds) between the first indication of the energy associated with the stop's oral release and the beginning of the regularly appearing waveform to the vowel following that stop. Thus, the VOT values of the four stop consonants produced by the subjects of all the three groups were obtained.

\subsection{Statistical analysis}

Extracted VOT values were tabulated and subjected to both descriptive and inferential statistics. Statistical Package for the Social Sciences (SPSS 11.5; SPSS Inc. Chicago, IL, USA) software was used to perform the statistical analysis. As a part of descriptive statistics, the mean and standard deviation values across the groups and gender were obtained. Multivariate Analysis of Variance (MANOVA) was performed as a part of inferential statistics to determine the between-subject effect of independent variables (age and gender) on dependent variables (VOT). Further, Repeated Measures of ANOVA was carried out to see the effect of different stop consonants on VOT values. All the statistical procedures were carried out at the alpha level of 0.05 (95\% confidence interval).

\section{Results}

The mean values of VOT across groups and gender are displayed in Table 1. As can be observed from table 1, Group 1 had the highest mean VOT values for all four stop consonants, and Group 3 had the lowest VOT values. It was also evident that the voiceless stop consonants $/ \mathrm{p} / \mathrm{and} / \mathrm{k} / \mathrm{had}$ small positive mean VOT values and voiced stop consonants /b/ and /g/ had large negative VOT values. Further, it was noted that among voiceless stop consonants /p/ had higher VOT values as compared to / $\mathrm{k} /$ and voiced stop consonants /b/ had higher VOT values as compared to /g/. It was also noted that the mean VOT values were higher among male subjects as compared to female subjects for all four stop consonants.

Table 1: Mean values of VOT across age and gender.

\begin{tabular}{ccccccc}
\hline Consonants & \multicolumn{2}{c}{ Group 1 } & \multicolumn{2}{c}{ Group 2 } & \multicolumn{2}{c}{ Group 3 } \\
& Male & Female & Male & Female & Male & Female \\
\hline /p/ & 17.50 & 13.57 & 14.52 & 12.49 & 11.58 & 9.93 \\
/k/ & 23.64 & 23.49 & 19.45 & 18.47 & 18.93 & 17.00 \\
/b/ & -60.07 & -68.53 & -43.44 & -53.99 & -41.29 & -46.13 \\
/g/ & -72.67 & -75.36 & -57.45 & -56.22 & -49.29 & -53.89 \\
\hline
\end{tabular}




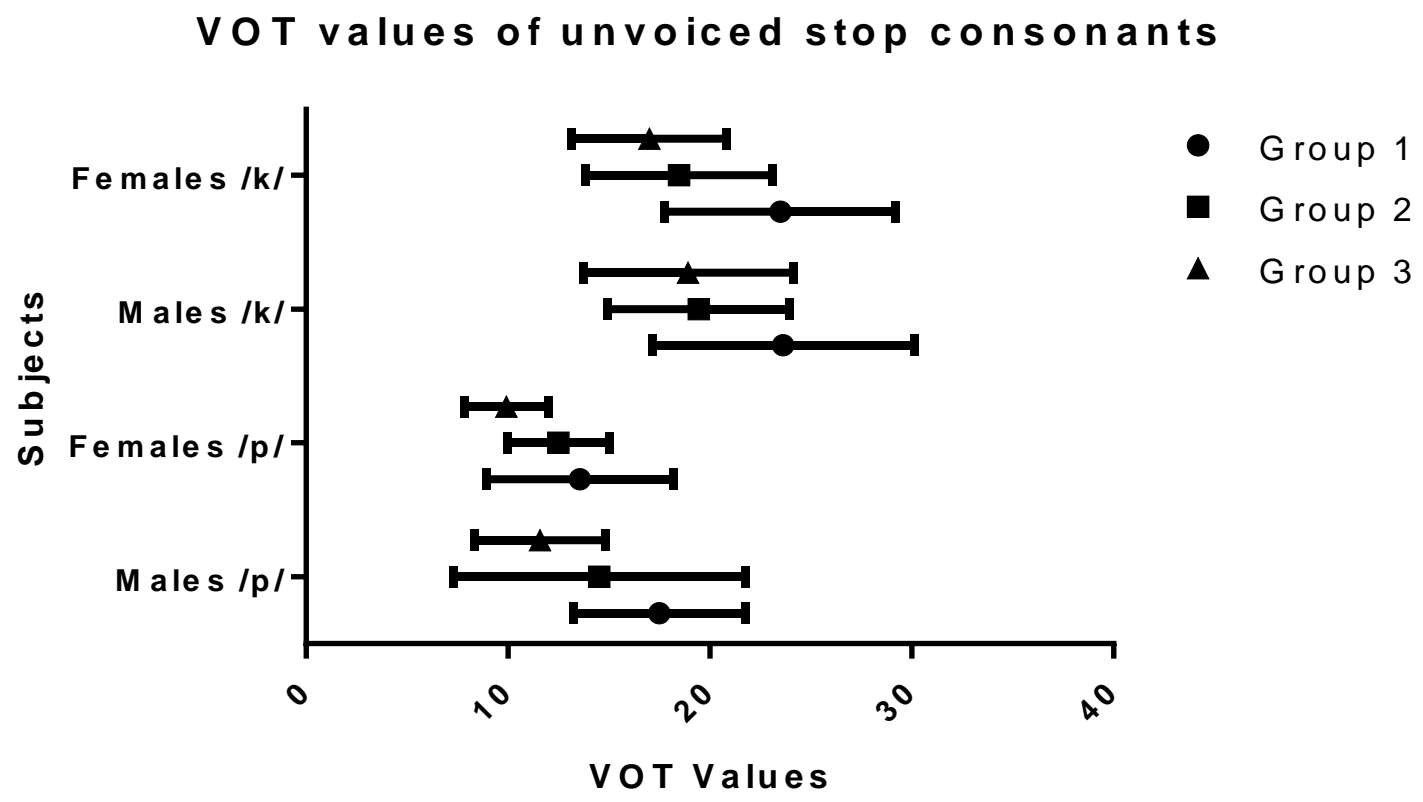

Figure 1. Mean and standard deviations of VOT for unvoiced stop consonants across age and gender.

\section{VOT values of voiced stop consonants}

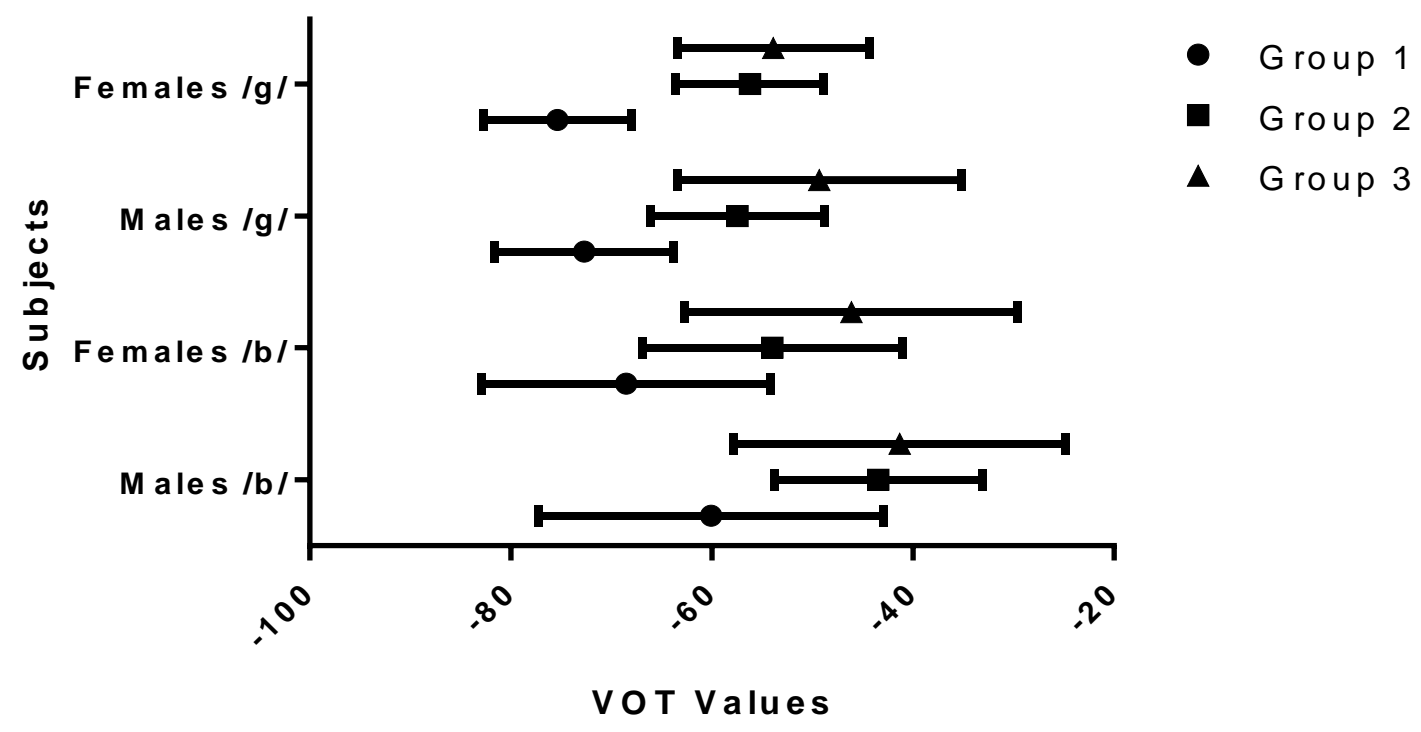

Figure 2. Mean and standard deviations of VOT for voiced stop consonants across age and gender.

*Correspondence: narasimhanslp@gmail.com

Tel: +919900789918

(C) University of Sri Jayewardenepura 
Table 2: Tests of between-subjects effect.

\begin{tabular}{cccc}
\hline & Mean Square & F value & Significance \\
\hline Age & 1492.00 & 10.85 & 0.00 \\
Gender & 685.36 & 4.98 & 0.03 \\
\hline
\end{tabular}

The results of MANOVA carried out to determine the effect of age and gender on VOT values have been presented in Table 2. As can be observed from Table 2, MANOVA showed that there was a significant effect of group on VOT values of stop consonants $/ \mathrm{p} /, / \mathrm{k} /, / \mathrm{b} /$ and $/ \mathrm{g} /$. Further, Scheffe's post hoc test was carried out to determine the presence of significant difference in VOT values between the each age groups. The results of the Scheffe's post hoc test (as shown in Table 3) revealed that there were significant differences in the VOT values between the subjects of group 1 and group 2, and between the subjects of group 1 and group 3. There were no significant differences in VOT values between the subjects of group 2 and group 3. Thus, the subjects of group 1 showed significantly higher VOT values for all four stop consonants as compared to the subjects of the other two groups. Significant gender-related effects in the VOT values were also observed where females showed longer VOT than male subjects.

Table 3. Results of Scheffe's post hoc test.

\begin{tabular}{cccc}
\hline Groups & Number & 1 & Subsets \\
& & -24.80 & 2 \\
Group 1 & 20 & & -18.27 \\
Group 2 & 20 & & -16.64 \\
Group 3 & 20 & & \\
\hline
\end{tabular}

The results of repeated measures of ANOVA carried out to determine the effects of voiced and voiceless stop consonants on the VOT values revealed that there were significant effects ( $\mathrm{F}=4907.95$, $/ \mathrm{P} /<0.05$ ) of stop consonants on VOT values. Pairwise comparison in the VOT values between the four stop consonants indicated that the voiced stop consonants /b/ and /g/ showed large negative VOT values and the voiceless stop consonants $/ \mathrm{p} /$ and $/ \mathrm{k} /$ showed small positive VOT values.

\section{Discussion}

The primary objective of the present study was to document the VOT of both voiced and voiceless stop consonants in Sinhala. The results of the present study showed that voiceless stop consonants had higher VOT measures than those of voiced stop consonants. Lisker \& Abramson (1967) reported from a perception experiment that a VOT of greater than $20 \mathrm{~ms}$ was perceived as a voiceless stop, whereas a VOT less than $20 \mathrm{~ms}$ was perceived as voiced stop by the listeners in the English language. Few researchers have disclosed that a positive VOT in the range of 30 to $100 \mathrm{~ms}$ were observed in voiceless plosives and voiced plosives showed negative VOT in the range of -100 to 0 milliseconds between the release of occlusion of stop consonant and the initiation of the vibration of the vocal folds in the English language (Docherty, 1992; Klatt, 1975; Lisker \& Abramson, 1964, 1967). The present study also showed similar results for VOT measures of stop consonants, indicating positive VOT for voiceless stops and negative VOT for voiced stops. Thus, the present study results are entirely in consonance with the studies mentioned above. The VOT values of adult Sinhala speakers obtained in the present study were also compared to the 
VOT values reported by the past studies on Indo-Aryan Languages spoken in India, including Assamese, Bengali, Gujarati, Hindi, Marathi, Oriya, Rajasthani, Kashmiri and Punjabi (Savithri \& Santhosh, 2003). The results showed that the VOT of both voiced and voiceless consonants in Sinhala speakers were lower than the VOT values reported for any of the Indo-Aryan languages of India (Savithri \& Santhosh, 2003). Thus, the hypothesis stating that 'there will be no significant differences between the VOT values of voiced and voiceless consonants in Sinhala language' was rejected. Therefore, it was concluded that the VOT values for both the voiced and voiceless consonants differ not only between different language families but also within the particular family of languages.

Past research on the cross-language study of VOT has concluded that the languages can be categorised under anyone groups with respect to their VOT values (Lisker \& Abramson, 1964). Languages under the first group have a negative VOT for voiced stops and medium length positive VOT for voiceless stops. Languages under the second group, all VOTs are positive, i.e. voiceless stops have long positive VOT and voiced stops have short positive VOTs (Lisker \& Abramson, 1964). The evidence from the present study revealed that the Sinhala language could be considered as a member of the first group as the voiced stop consonants (/b/ and /g/) showed negative VOT and the voiceless stop consonants $(/ \mathrm{p} /$ and $/ \mathrm{k} /)$ showed positive VOT.

The second objective of the study was to investigate the effect of age on the VOT values of voiced and voiceless stop consonants. A literature review shows that the VOT measure of stop consonants reliably differed across age (Stölten et al., 2015; Yu et al., 2015). According to Vickie et al. (2013), production of a longer VOT and higher variability in younger children markedly in the age group 4-5 years for the production of $/ \mathrm{k} /$ in multi-syllable sequence when compared to older groups (Yu et al., 2015). In the Indian context, Savithri, Pushpavathi, \& Sujatha, (2007) found that as age increases, mean VOT tends to be shorter (Savithri et al., 2007). According to Narasimhan \& Nataraja (2016), overall changes in anatomy, physiology, and phonetic influences during development might be the reason for these changes in VOT values with the increase in age (Narasimhan \& Nataraja, 2016). Whiteside \& Marshall (2001) put forward two explanations for decreasing VOT with increasing age. One is the anatomical changes in vocal tract size occurring in males during puberty, and second is the sociophonetic influences in which children may be learning the adult-like VOT pattern (Whiteside \& Marshall, 1998). The present study also showed similar evidence reflecting higher VOT values in children followed by adults and elderly individuals. Thus, the present study results reconfirm the results of all the earlier mentioned studies. Therefore, the hypothesis stating that 'there will be no significant differences in the VOT values between the age groups in Sinhala language' was rejected.

The third objective of the study was to investigate the gender-linked differences in VOT. The results of the current investigation also revealed that there was a significant effect of gender on the VOT values where female subjects showed significantly higher values of VOT compared to the male subjects. Earlier studies have reported mixed results on gender-linked differences in VOT. Several studies have shown gender-linked differences in VOT values. Among these studies, some researchers have reported longer VOT values in females (Karlsson et al., 2004; Robb et al., 2005; Ryalls et al., 1997; Swartz, 1992; Whiteside \& Marshall, 2001), and other studies have found longer VOT values in males (Smith, 1978). These studies have attributed the gender-linked differences in temporal aspects of speech production to the differences in the vocal anatomy between males and females (Robb et al., 2005). Some studies have also reported no differences in VOT between male and female subjects (Ryalls et al., 2004; Sweeting \& Baken, 1982). Madhu, Mahendra, \& Sreedevi (2014) investigated the gender-linked differences in the 
production of VOT among Telugu speakers and found that there was no significant difference in VOT values of voiced and voiceless stops between males and females (Madhu et al., 2014). Narasimhan \& Nataraja (2016) reported no statistically significant difference VOT values of both voiced and unvoiced stop consonants between both the genders (Narasimhan \& Nataraja, 2016). Therefore, the results of the present study were in accordance with findings of the earlier studies that longer VOT in female subjects compared to males (Karlsson et al., 2004; Robb et al., 2005; Ryalls et al., 1997; Swartz, 1992; Whiteside \& Marshall, 2001). Therefore, the hypothesis stating that 'there will be no significant differences in the VOT values between the genders in Sinhala language' was rejected.

Given that the dialectal variations can affect VOT values, generalisations of the data ought to be made with some caution as the present study was limited to the speakers of the central province dialect of Sinhala. Future investigations of VOT in speakers of Southern Province dialect of Sinhala can help in better generalisations of the study results. Further, the passage used in the present study was not standardised in Sinhala. Nevertheless, the results of this study can be used as a reference for other studies focussing on the acoustic and temporal parameters of speech among Sinhala speakers. Supplementary investigations on the normative aspects of VOT among the Sinhala population would provide additional insights and validated tools for indexing the articulatory and acoustic characteristics of stop consonants in Sinhalese.

\section{Conclusion}

The present study analysed VOT in two voiced and two voiceless stop consonants produced by native Sinhala speaking children, adults, and elderly individuals. The results showed that the voiced stop consonants had significantly longer VOT values compared to those of voiceless stop consonants. The VOT values were significantly different between children, adults, and elderly Sinhala speakers. There were also significant differences in VOT between the male and female individuals. Thus, the study was a preliminary attempt to document the effect of age, consonants, and gender on the VOT in the Sinhala language. However, foraging studies can be carried out on documenting the developmental aspects of VOT among Sinhala speaking children of various age groups. Future studies on the normative aspects of VOT among the Sinhala population of various age groups would help to document the relationship between language and phonetic factors.

\section{References}

Abramson, A. S., \& Lisker, L. (1973). Voice-timing perception in Spanish word-initial stops. Journal of Phonetics, 1(1), 1-8. https://doi.org/10.1016/s0095-4470(19)31372-5

Abramson, A. S., \& Whalen, D. H. (2017). Voice Onset Time (VOT) at 50: Theoretical and practical issues in measuring voicing distinctions. Journal of Phonetics, 63, 75-86. https://doi.org/10.1016/j.wocn.2017.05.002

Alotaibi, Y. A., \& AlDahri, S. S. (2011). Investigating VOTs of Arabic stops /b, k/ with comparisons to other languages. Proceedings - 4th International Congress on Image and Signal Processing, CISP 2011, 5, 2413-2417. https://doi.org/10.1109/CISP.2011.6100669

ANSI S3.1. (2013). Maximum Permissible Ambient Noise Levels for Audiometric Test Rooms. American National Standards Institute.

Bae, Y. (2020). Effects of Age on Voice Onset Time and Variability in Children with Repaired Cleft Palate. Folia Phoniatrica et Logopaedica, 72(1), 36-42. https://doi.org/10.1159/000496085

Ballard, K. J., Robin, D. A., Woodworth, G., \& Zimba, L. D. (2001). Age-Related Changes in Motor 
Control during Articulator Visuomotor Tracking. Journal of Speech, Language, and Hearing Research, 44(1-4), 763-777. https://doi.org/10.1044/1092-4388(2001/060)

Barton, D., \& Macken, M. A. (1980). An instrumental analysis of the voicing contrast in word-initial stops in the speech of four-year-old English-speaking children. Language and Speech, 23(2), 159169. https://doi.org/10.1177/002383098002300203

Bóna, J. (2014). Voice onset time and speakers' age: Data from Hungarian. Clinical Linguistics and Phonetics, 28(5), 366-372. https://doi.org/10.3109/02699206.2013.875593

Cho, T., \& Ladefoged, P. (1999). Variation and universals in VOT: Evidence from 18 languages. Journal of Phonetics, 27(2), 207-229. https://doi.org/10.1006/jpho.1999.0094

Davis, K. (1990). VOT development in Hindi and in English. The Journal of the Acoustical Society of America, 87, S120-S120. https://doi.org/10.1121/1.2027880

Docherty, G. (1992). The timing of voicing in British English obstruents. New York: Foris.

Karlsson, F., Zetterholm, E., \& Sullivan, K. P. H. (2004). Development of a Gender Difference in Voice Onset Time. Proceedings of the 10th Australian International Conference on Speech Science \& Technology, 316-321.

Kent, R. D. (1976). Anatomical and neuromuscular maturation of the speech mechanism: Evident from acoustic studies. Journal of Speech and Hearing Research, 19, 421-445.

Klatt. (1975). Voice onset time, frication, and aspiration in word-initial consonant clusters. Journal of Speech and Hearing Research, 18(4), 686-706.

Koenig, L. L. (2001). Distributional characteristics of VOT in children's voiceless aspirated stops and interpretation of developmental trends. Journal of Speech, Language, and Hearing Research, 44(5), 1058-1068. https://doi.org/10.1044/1092-4388(2001/084)

Lisker, L., \& Abramson, A. S. (1964). A cross-language study of voicing in initial stops: Acoustical measurements. Word Journal Of The International Linguistic Association, 20(3), 384-422.

Lisker, L., \& Abramson, A. S. (1967). Some effects of context on voice onset time in english stops. Language and Speech, 10(1), 1-28. https://doi.org/10.1177/002383096701000101

Lisker, L., \& Abramson, A. S. (1971). Distinctive Features and Laryngeal Control. Language, 47(4), 767. https://doi.org/10.2307/412155

Lundeborg, I., Larsson, M., Wiman, S., \& McAllister, A. M. (2012). Voice onset time in Swedish children and adults. Logopedics Phoniatrics Vocology, 37(3), 117-122. https://doi.org/10.3109/14015439.2012.664654

Ma, J., Chen, X., Wu, Y., \& Zhang, L. (2018). Effects of age and sex on voice onset time: Evidence from Mandarin voiceless stops. Logopedics Phoniatrics Vocology, 43(2), 56-62. https://doi.org/10.1080/14015439.2017.1324915

Madhu, S. R., Kumar, M., \& Sreedevi, N. (2014). Voice onset time across gender and different vowel contexts in Telugu. Language in India, 14(2), 252-263.

Manjunath, N., Sneha, M., \& Narasimhan, S. V. (2010). Variation of Voice Onset Time (VOT) in Kannada Language. Language in India.

Mitleb, F. (2001). Voice onset time of Jordanian Arabic stops. The Journal of the Acoustical Society of America, 109(5), 2474-2474. https://doi.org/10.1121/1.4744787

Narasimhan, S. V, \& Nataraja, N. P. (2016). Development of Voice Onset Time in the Speech of Kannada Speaking Children. AYJNIHH Journal of Communication Disorders, 1(1), 10-19.

Olson, D. E. (2017). Voice onset time in arabic and english stop consonants. Undergraduate Research Journal, S1, 29-48.

Peng, Chen, \& Lee. (2014). Voice onset time of initial stops in Mandarin and Hakka: Effect of gender. Taiwan Journal of Linguistics, 12(1), 63-79. https://doi.org/10.6519/TJL.2014.12(1).3 
Robb, M., Gilbert, H., \& Lerman, J. (2005). Influence of Gender and Environmental Setting on Voice Onset Time. Folia Phoniatrica et Logopaedica, 57(3), 125-133.

https://www.karger.com/DOI/10.1159/000084133

Ryalls, J., Simon, M., \& Thomason, J. (2004). Voice Onset Time production in older Caucasian- and African-Americans. Journal of Multilingual Communication Disorders, 2(1), 61-67. https://doi.org/10.1080/1476967031000090980

Ryalls, J., Zipprer, A., \& Baldauff, P. (1997). A preliminary investigation of the effects of gender and race on Voice Onset Time. Journal of Speech and Hearing Research, 40.(3), 642-645.

Savithri, Pushpavathi, \& Sujatha. (2007). Development of voicing contrast: A comparison of VOT in stop perception. Journal of All India Institute of Speech and Hearing, 26.

Savithri, S. R., \& Santhosh, M. (2003). Voicing Contrast in Indian Languages: Some Acoustic Measurements. Journal of the Acoustical Society of India, 31, 122-125.

Smith, B. (1978). Effects of place of articulation and vowel environment on voiced stop. Glossa, 12, $163-175$.

Smith, B. L., Wasowicz, J., \& Preston, J. (1987). Temporal characteristics of the speech of normal elderly adults. Journal of Speech and Hearing Research, 30(4), 522-529. https://doi.org/10.1044/jshr.3004.522

Stölten, K., Abrahamsson, N., \& Hyltenstam, K. (2015). Effects of age and speaking rate on voice onset time: The Production of Voiceless Stops by Near-Native L2 Speakers. Studies in Second Language Acquisition, 37(1), 71-100. https://doi.org/10.1017/S0272263114000151

Swartz, B. L. (1992). Gender Difference in Voice Onset Time. Perceptual and Motor Skills, 75(3), 983992. https://doi.org/10.2466/pms.1992.75.3.983

Sweeting, P. M., \& Baken, R. J. (1982). Voice onset time in normal-aged population. Journal of Speech and Hearing Research, 25(1), 129-134.

Torre, P., \& Barlow, J. A. (2009). Age-related changes in acoustic characteristics of adult speech. Journal of Communication Disorders, 42(5), 324-333. https://doi.org/10.1016/j.jcomdis.2009.03.001

Whiteside, S. P., Dobbin, R., \& Henry, L. (2003). Patterns of variability in voice onset time: A developmental study of motor speech skills in humans. Neuroscience Letters, 347(1), 29-32. https://doi.org/10.1016/S0304-3940(03)00598-6

Whiteside, S. P., \& Marshall, J. (1998). Voice onset time patterns in 7-, 9-, and 11- year old children. In Proceedings of the 5th International Conference on Spoken Language Processing. Sheffield University, UK.

Whiteside, S. P., \& Marshall, J. (2001). Developmental trends in voice onset time: Some evidence for sex differences. Phonetica, 58(3), 196-210. https://doi.org/10.1159/000056199

Yu, V. Y., De Nil, L. F., \& Pang, E. W. (2015). Effects of Age, Sex and Syllable Number on Voice Onset Time: Evidence from Children's Voiceless Aspirated Stops. Language and Speech, 58(2), 152-167. https://doi.org/10.1177/0023830914522994.

Zlatin, M. A., \& Koenigsknecht, R. A. (1976). Development of the Voicing Contrast: A Comparison of Voice Onset Time in Stop Perception and Production. Journal of Speech and Hearing Research, 19(1), 93-111. 